\title{
The Survival of Market Orientation through Artificial Selection
}

\author{
Ryusuke KOSUGE ${ }^{\text {a) }}$ and Nobuo TAKAHASHI ${ }^{\text {b) }}$
}

\begin{abstract}
Observations of a Japanese automobile dealer company shifting from a selling orientation to a market orientation revealed the following: (1) A market-oriented program with a process and team orientation threatened the self-concept of the sales force and was rejected by most of them; (2) when three out of 54 shops, or only approximately $5 \%$, appeared to be developing a form of market orientation, the top management selected managers of those three shops as well as changed the existing evaluation and reward system, which caused market orientation to take precedence in the organization. It should be noted that what happened at this company was contrary to natural selection or competitive isomorphism. At first, these three shops performed so poorly that they could well have been "selected out." However, the top management allowed the three shops to survive and, when the time was ripe, deliberately made an effort to spread the form of market orientation within the organization. In essence, it is suggested that the key mechanism of developing a market
\end{abstract}

\footnotetext{
a) Graduate School of Management, Ritsumeikan University, 2-150 Iwakuracho, Ibaraki, Osaka, Japan, kosuge@fc.ritsumei.ac.jp

b) Graduate School of Economics, University of Tokyo, 7-3-1 Hongo, Bunkyo-ku, Tokyo, Japan, nobuta@e.u-tokyo.ac.jp

A version of this paper was presented at the ABAS Conference 2016 Autumn (Kosuge, 2016).

(C) 2016 Ryusuke Kosuge and Nobuo Takahashi. This is an Open Access article distributed under the terms of the Creative Commons Attribution License, which permits unrestricted reuse, distribution, and reproduction in any medium, provided the original work is properly cited.
} 
orientation is institutional isomorphism through artificial selection.

Keywords: market orientation, automobile dealer, isomorphism, artificial selection

\section{Introduction}

Market orientation has been conceptualized as an organizational culture and a resulting behavior for creating superior value for customers (Kohli \& Jaworski, 1990; Narver \& Slater, 1990). Throughout the years of research, it has been shown to have a positive impact on performance (Kirca, Jayachandran, \& Bearden, 2005). As the importance of a market orientation in business becomes evident, more attention is being given to the question of "How can it be developed?" Quantitative research has shown that top management focus, inter-departmental coordination, and a market-based reward system act as antecedents to a market orientation (Kirca et al., 2005). However, qualitative studies on the mechanisms of developing a market orientation (Gebhardt, Carpenter, \& Sherry, 2006; Kennedy, Goolsby, \& Arnould, 2003) have only recently begun to appear. ${ }^{1}$

One problem with prior research is that it does not consider organizational path dependencies. In some cases, path dependency may make it almost impossible to develop a market orientation. The most extreme case is when a homogeneous sales organization, which for many years had the opposite of a market orientation, namely a selling orientation, aims to develop a market orientation. According to the theory of evolution in organizational change literature (Van de Ven \& Poole, 1995), even when a market orientation is formed locally,

1 See Kosuge (2007a, 2007b) for prior research on this aspect. 
it may be "selected out" by natural selection. In such circumstances, just how can a market orientation be developed? Examining this issue will add new angles to the existing literature on market orientation.

This study presents a case of a Japanese automobile dealer that has shifted from a traditional selling orientation to a process-focused market orientation (Kosuge, 2011). What occurred at this company between 2001 and 2009 was not natural selection. Out of 54 shops competing with one another, only three started to develop a form of market orientation. They were performing poorly and, therefore, could have been "selected out," if left to their own devices. However, the top management allowed the three shops to survive and deliberately made an effort to spread the form of market orientation within the organization. In other words, institutional isomorphism occurred in these 54 shops through artificial selection.

\section{Phase 1: Resistance from a Great Majority}

Sales staff at this company was given short-term quotas for new car sales. Their primary focus was on achieving those quotas. The sales force disregarded customers' needs and did whatever they could to sell what the company wants to sell. There was a lack of organizational effort to understand market trends and create value for customers. Just as with other companies in this industry, the company had pursued to maximize sales over the past decades. However, the top management started to doubt the long-term sustainability of this business approach and began a program to shift toward a market orientation in $2001 .{ }^{2}$

In an organizational culture where "results are everything," the sales staff, who had focused only on their performance, perceived this

2 This can also be seen as a shift from exploitation, which led to over-adaptation to a market environment, toward exploration (Sato, 2012). 
program to be contradictory to the traditional sales style. Also, when the top management emphasized the importance of processes, it was met with resistance.

“Think about it. Don't you wonder what process there is in a sales company? It's ridiculous! How many have you sold?... So no matter what you try, if your numbers don't improve, it's all the same to the guys upstairs."

"You can't do anything if all you're thinking about is short-term goals like having to reach a certain sales target every day."

The greater the emphasis on a process orientation, the more the sales force held on to their traditional sales style, noting that "they can't complain as long as we just achieve good results."

In addition, a "team orientation" means that salespeople work together to contact customers, share their know-how with each other, and function as an organization. This kind of thinking received the following response.

"The truth is that a company is a collection of individuals, so if everyone does their job properly we won't be blamed. If you don't like the manager yelling at you, then don't give him a reason to do so."

Various attempts by the top management to facilitate the new way of doing things were rejected. One example of this was the introduction of the "follow-up cards." The main aim was to contact customers before their vehicle inspection expiration dates "with good quality (right information), without omission, at the right timings." This set-up was originally proposed by the automaker that wanted its dealers to become market-oriented. Based on customer data entered into a computer, a "follow-up card" and a direct mail would be printed out as a set. Of these, a direct mail would then be sent off to the customer 48 days prior to their inspection expiration date. This 
would be followed by phone calls 45, 30, and 20 days prior to the same date. Sales staff was expected to enter the results of their efforts on the "follow-up card" and hand it in to the shop's manager. The manager would then give feedback to the sales staff.

If the contact attempt succeeds and the customer comes to the service workshop for a car inspection, there will be new sales opportunities. During the 45-minute wait for the inspection, sales staff could take the customer into the show room and recommend a new car as well other products and services. Another important aspect of "follow-up cards" is that they are stored in a large organizing shelf in the office room. In this way, the entire contact process becomes visible, which allows the sales force to share their responsibilities when necessary.

However, this new way of doing things was met with various types of resistance. Because the salespeople felt that the idea was "ridiculous" or thought that their workload would increase, many of them did not bother to send the direct mails or use "follow-up cards." There were some who tried to use "follow-up cards", but in many cases, their cards ended up on or in their desks. Eventually, in most shops, the organizing shelf was shoved in the corner.

Max Weber pointed out the existence of a "shell" (Takahashi, 2015). When one's environment or surroundings undergo a major change, people withdraw into their "shells". Calling this "rejection" is too one-sided, so researchers have instead used the terms "self-concept" (Eilam \& Shmair, 2005) or "self-identity" (Weick, 1995). The main argument here is that people exhibit negative reactions to changes that threaten their "self-concept" or "self-identity." In this case as well, if our observations end with this phenomenon, we may come to the conclusion that "management policies that threaten people's self-concept or self-identity will fail." 


\section{Phase 2: Survival of a Small Minority}

Actually, there were three shops where "follow-up cards" came to be accepted. The managers of the three shops began to use "follow-up cards" proactively as a communication tool to help salespeople build customer-focused thinking and behavior. Rather than focusing on monitoring and control of contact activities, they tried to have meaningful dialogue with each salesperson regarding what went wrong and what went right. For them, "follow-up cards" were nothing but a trigger for dialogue. In many cases, they wrote comments on the cards to provide advice, direction, and support to salespeople. Of course, it is time consuming for the managers to write comments on each "follow-up card." However, these managers clearly recognized that it was their job to engage with salespeople so that they can engage with customers.

If the manager had instead done nothing but check the status of orders and the achievement of sales quotas without caring about salespeople's contact activities, these shops would have repeated the same problem. If salespeople were meeting their quotas for a particular month, then they did not have the incentive to contact more customers within the month. They would rather focus on the following month's quotas. Therefore, some-customers would fail to meet their inspection deadlines.

Also, the individualistic way of doing things was far from ideal for customers. For example, if a customer of Salesperson A comes into the shop while the salesperson is working outside the office, the customer might be told, "I can't help you because Salesperson A is out of the office." This would be a lost sales opportunity. Instead, it would be better to respond,

"Salesperson A is out of the office, but I would be happy to help you."

Essentially, the person should be labeled as the shop's customer or 
the company's customer rather than "Salesperson A's customer." Such a shared responsibility, with the help of shared customer data, enables everyone to respond to each customer flexibly. Rationally speaking, it is better to form teams that work in a spirit of active cooperation and commitment instead of having salespeople sell individually and compete with their colleagues in a sales tug-of-war. Customers prefer such a team approach as it puts them more at ease.

That said, these three shops comprised only $5 \%$ of all shops, which is within statistical error. In addition, these three shops were performing poorly; one of them was even ranked the lowest. In any case, they were less fit and therefore were prime candidates for being "selected out" (i.e., eliminated through natural selection). Of course, many researchers will conclude that "management policies that threaten people's self-concept or self-identity will fail." However, the reality turned out to be different in this case.

By using "follow-up cards," salespeople at these three shops learned to focus on each customer regardless of their responsibilities. Also, they improved work together through experiments, which gradually became second nature to them. As they experienced more and more success by using the "follow-up cards," these shops began to function as a cohesive organization. This resulted in gradual improvement of the shops' overall numbers. In this way, they shot up to the highest ranked shops, including the one that had been at the bottom. In the end, the top management clearly recognized that these shops were successful in terms of market orientation.

In fact, the real reason these three shops survived despite the force of natural selection was due to the artificial selection done by the top management. In 2007, the top management promoted the managers of the three shops to general manager positions at the headquarters and put them in charge of training other shops to 
diffuse the experience of the three shops. In addition, the top management revised the evaluation and reward system, the intent of which was to promote teamwork that had developed at these three shops: Bonuses had previously been awarded to individuals based on their personal sales performance. Instead, team bonuses were distributed equally among everyone working at the shop based on the shop's performance.

\section{Competitive Isomorphism vs. Institutional Isomorphism}

The natural selection that researchers like to use is, in a certain sense, a convenient rationalization. In contrast, the real business world is harsh, and to say "95\% of the shops failed, so mine failed too" is not acceptable if there is a visible example of success, even if it accounts for only $5 \%$. That example should be imitated, although $5 \%$ can be ignored statistically. Imitating a successful practice is easy in contrast with the difficulties faced by the minority of managers.

"The iron cage revisited" (DiMaggio \& Powell, 1983) ${ }^{3}$ asks "why there is such startling homogeneity of organizational forms and practices (DiMaggio \& Powell, 1983, p. 148)." With this question, the article calls the process of homogenization of organizations in the same organizational field "isomorphism." Isomorphism can be broadly divided in the following two categories.

(1) Competitive isomorphism, which corresponds to a functional fit with an environment

(2) Institutional isomorphism, which corresponds to such cultural and social fits as coercive isomorphism, mimetic isomorphism, and normative isomorphism.

3 The "iron cage" originates from Weber (1930), but it has been noted that Parsons probably should have translated "Gehäuse" in Weber (1920) as "shell" (Takahashi, 2013, 2015). 
With respect to (1) competitive isomorphism, entities that have survived natural selection through competition for survival eventually become similar to one another as a result of conforming to the functional characteristics of their environment. In fact, many people base their arguments on this implicit assumption, and many also implicitly view survivors as surviving because of their superiority. But is it true that the survivors of natural selection survived because of their superiority? In fact, in competitive isomorphism, there are cases when isomorphism does not advance in a superior form. This is a critical point, a typical example of which is the case above, where the "follow-up cards" were rejected. This is exactly why DiMaggio \& Powell (1983) proposed the artificial selection of type (2) as an example of isomorphism. In fact, in the case presented above, top management focused on the three shops, which were exceptions to the rule, and pushed an institutional isomorphism based on artificial selection.

\section{Concluding Remarks}

This study identified the crucial and nuanced role played by top management in developing a market orientation. Even though prior research has discussed the importance of top management's vision and displays of commitment (Kennedy et al., 2003; Narver, Slater, \& Tietje, 1998), a market orientation cannot be developed with those attributes alone, as can be seen in the case presented here. Top management should focus on exceptional phenomena that may well be eliminated through natural selection and push for institutional isomorphism based on artificial selection.

This notion is not limited to the development of a market orientation. For example, wild bananas have seeds but the bananas we eat do not. In a world of natural selection, seedless bananas would immediately die out or would merely be local and accidental 
phenomena. Just as seedless bananas have no way to propagate on their own, bananas with seeds should naturally be able to survive and multiply. However, that is not what we see now. This is because humans take cuttings from mutant (triploid) seedless bananas and continually split and, thereby, increase them. ${ }^{4}$ Seedless bananas have, for the most part, overtaken bananas with seeds because of artificial selection.

If things were left to natural selection, we would not be able to enjoy delicious bananas. The same thing happens in organizations. "Breeders" are critical for corporations and organizations. In the case of the automobile dealer company discussed in this study, the company's top management acted as breeders. When the top management find desirable forms to achieve their goals, even if they are exceptional and statistically insignificant, it is crucial to diffuse them throughout the organization. In natural selection, superior forms do not necessarily spread within an organization and "shells" tend to remain intact. It is humans who break "shells."

\section{Acknowledgements}

This work was supported by JSPS Grants-in-Aid for Publication of Scientific Research Results, Grant Number JP16HP2004 and JSPS KAKENHI Grant Number JP26380454 for FY 2014-2018.

\section{References}

DiMaggio, P. J., \& Powell, W. W. (1983). The iron cage revisited: Institutional isomorphism and collective rationality in organizational fields. American Sociological Review, 48, 147-160.

4 http://www.banana.co.jp/ 
Eilam, G., \& Shamir, B. (2005). Organizational change and self-concept threats: A theoretical perspective and a case study. Journal of Applied Behavioral Science, 41, 299-421.

Gebhardt, G. F., Carpenter, G. S., \& Sherry, J. F., Jr. (2006). Creating a market orientation: A longitudinal, multi-firm, grounded analysis of cultural transformation. Journal of Marketing, 70, 37-55.

Kennedy, K. N., Goolsby, J. R., \& Arnould, E. J. (2003). Implementing a customer orientation: Extension of theory and application. Journal of Marketing, 67, 67-81.

Kirca, A. H., Jayachandran, S., \& Bearden, W. O. (2005). Market orientation: A meta-analytic review and assessment of its antecedents and impact on performance. Journal of Marketing, 69(2), 24-41.

Kohli, A. K., \& Jaworski, B. J. (1990). Market orientation: The construct, research propositions, and managerial implications. The Journal of Marketing, 54(2), 1-18.

Kosuge, R. (2007a). Internal effects of customer contact within service organizations: Implications for developing a customer-oriented organizational culture. Annals of Business Administrative Science, 6, 1-14. doi: 10.7880/abas.6.1

Kosuge, R. (2007b). Kokyaku shikou kara shijyou shikou he: Riron to sokutei [From customer orientation to market orientation: Theory and measurement]. Akamon Management Review, 6(7), 243-266 (in Japanese).

Kosuge, R. (2011). The dilemma of developing market orientation. (Unpublished doctoral dissertation). Graduate School of Economics, University of Tokyo, Tokyo.

Kosuge, R. (2016, November). The role of continuous improvement in the relationship between market orientation and sales productivity. Paper presented at ABAS Conference 2016 Autumn, University of Tokyo, Japan.

Narver, J. C., \& Slater, S. F. (1990). The effect of market orientation on business profitability. Journal of Marketing, 54, 20-35.

Narver, J. C., \& Slater, S. F., \& Tietje, B. (1998). Creating a market orientation. Journal of Market-Focused Management, 2(3), 241-255.

Sato, H. (2012). Routine-based view of organizational learning and 
mechanisms of myopia. Annals of Business Administrative Science, 11, 45-54. doi: 10.7880/abas. 11.45

Takahashi, N. (2013). Kara [Shell]. Kyoto, Japan: Minervashobo (in Japanese).

Takahashi, N. (2015). Behind the shell: Rigid persons clung onto it. Annals of Business Administrative Science, 14, 1-14. doi: 10.7780/abas.14.1

Van de Ven, A. H., \& Poole, M. S. (1995). Explaining development and change in organizations. Academy of Management Review, 20(3), 510-540.

Weber, M. (1920). Die protestantische Ethik und der Geist des Kapitalismus. Tübingen, Germany: Verlag von J. C. B. Mohr.

Weber, M. (1930). The protestant ethic and the spirit of capitalism. (Talcott Parsons, Trans.). New York, NY: Charles Scribner's Sons. (Original work published 1920)

Weick, K. E. (1995). Sensemaking in organizations. Thousand Oaks, CA: Sage. 